\title{
'Growth with equity' and regional development: distributional consequences of agglomeration in Taiwan
}

\author{
Martin Andersson and Martin Klinthäll
}

\section{Linköping University Post Print}

\section{Tweet}

N.B.: When citing this work, cite the original article.

This is an electronic version of an article published in:

Martin Andersson and Martin Klinthäll, 'Growth with equity' and regional development: distributional consequences of agglomeration in Taiwan, 2015, Journal of the Asia Pacific Economy, (20), 2, 271-289.

Journal of the Asia Pacific Economy is available online at informaworld ${ }^{\mathrm{TM}}$ :

http://dx.doi.org/10.1080/13547860.2014.964965

Copyright: Taylor \& Francis (Routledge): SSH Titles http://www.routledge.com/

Postprint available at: Linköping University Electronic Press

http://urn.kb.se/resolve?urn=urn:nbn:se:liu:diva-111490 


\title{
'Growth with equity' and regional development: distributional consequences of
}

\author{
agglomeration in Taiwan
}

Martin Andersson ${ }^{a^{*}}$ and Martin Klinthäll ${ }^{b}$

a Department of Economic History, Lund University, Sweden;

${ }^{b}$ Department of Management and Engineering, Linköping University, Sweden

\begin{abstract}
This study investigates long-term distributional effects of regional agglomeration. We analyse changes in relative incomes for different educational and occupational categories in Taiwan from 1976-2006, a period during which the country underwent fundamental structural change from labour to knowledge intensive industry and increasing globalisation of the economy. Long-term patterns derived from repeated estimations of cross-sectional micro level data from 31 consecutive annual household surveys show that less educated groups are not systematic losers of the transformation as positive externalities of agglomeration are both significant and widespread in the leading region. The famous pattern of 'growth with equity' in Taiwan has, however, become a regional rather than national feature.
\end{abstract}

Keywords: Taiwan; growth with equity; income distribution; regional agglomeration; structural change

JEL classifications: O18, O53, N15, N95, R11, R12

\section{Introduction}

The literature on geographic agglomeration, growth and income distribution has over the last few decades grown immensely (for instance, see reviews by Rey and Janikas 2005; Kim 2008; Ascani et al. 2012). It is widely acknowledged that agglomeration is positively correlated with innovative activities and growth (for instance, Jaffe et al. 1993; Storper 1997). Consequently, geographical agglomeration might generate regional income divergence at the sub-national level. A central question is the extent to which the growth

${ }^{*}$ Corresponding author. Email: martin.andersson@ekh.lu.se 
and innovation induced by agglomeration create spill-overs, and whether such spill-overs are limited to certain groups or if they are of a more general character (see Myrdal 1957; Hirschman 1958; Fujita and Thisse 2003).

This study focuses on distributional effects of regional agglomeration for different categories of the work force over time, both within and across sub-national regions in Taiwan from 1976 to 2006 on the basis of household data. It has been widely recognised that inequality over the last few decades has increased among the East Asian 'growth with equity' cases (Japan, South Korea and Taiwan), and some suggest that it has 'reached historic heights' (Feng 2011: 7). It is also acknowledged that economic activities have increasingly become concentrated in the northern region of Taiwan. The purpose of the paper is to take stock of this increase in inequality and examine whether positive externalities of agglomeration in northern Taiwan are widely diffused or biased across occupational and educational categories within this leading region. We also examine to what extent comparable categories outside the leading region are affected. In the analysis, we are primarily concerned with relative changes over time rather than absolute changes.

The reasons behind increasing income inequality in a regional perspective are many. There might be regional differences in levels of education, type of industry and occupations and demographic characteristics of the household that allow for certain regions to move ahead. There might also be inter-regional differences in the evolution of prices and there might be some kind of selection bias in the migration of labour. In the present paper, we employ an empirical strategy to capture as far as possible only the income effect of residing inside or outside of a geographically agglomerated region. Hence, we attempt to control for regional biases in the above factors to grasp the sheer income effect of agglomeration. We then argue that if regional per capita income in a leading region increases regardless of 
occupation and education, it suggests that the income effect of agglomeration is general in nature. The implications are that the regional labour market is reasonably well integrated allowing e.g., spill-over effects and sharing of productive resources between occupational groups in the leading region. It would signify a situation where Marshallian externalities, facilitated by proximity, are spread out in the region (for instance, Marshall 1890; Glaeser et al. 1992). If, on the other hand, income increases only for selected educational and occupational categories that are distinguished winners in the process, the interpretation is the existence of weaker linkages or labour market bottle necks. One can then suspect insufficient Marshallian externalities and that the pooling of skilled workers is stronger than skill spill-overs. One of the crucial aspects to consider is whether low-end occupations and educational levels in the leading region are falling behind their counterparts in the nonagglomerating region. If the positive locational effect is selective, enjoyed only by the higher skilled work force in the agglomerating region, regional disparities are likely to be sustained.

Over the last decades, the world economy has globalised, and both developed and developing countries alike have started to shift away from labour intensive manufacturing towards ICT (Information and Communications Technology) and other skill intensive industries, often creating geographical agglomeration. Although the causal relations are yet to be identified, and are beyond the reach of this paper (but see, for instance, Goldin and Katz 2008; Acemoglu and Autor 2011 for discussion of the general mechanisms), it seems as if these contextual changes are closely associated with regional income divergence (Saxenian 1994; Fagerberg and Verspagen 1996; Petrakos 2001; Puga 2002; Sanchez-Reaza and Rodríguez-Pose 2002; Zhang and Zhang 2003; Rodríguez-Pose and Gill 2006; Hamaguchi 2009). Whether or not this leads to disproportional income benefits to the already advantaged groups is one of the most pressing questions for scholars and policy makers alike 
(for instance, Fujita and Thisse 2003; Dupont 2007; WDR 2009; OECD 2011). The growth process in Taiwan during the closing decades of the $20^{\text {th }}$ and beginning of the $21^{\text {st }}$ centuries makes it a particularly suitable case for investigating these matters. The stylised facts of Taiwan regarding both personal and spatial income inequality establish that Taiwan has, for long, been a case of 'growth with equity' (Fei et al.1979; Ho 1979). During the thirty years under investigation (1976-2006), Taiwan made a shift from a labour intensive light manufacturing economy to a skill- and technology-intensive economy and a simultaneous process of integration into the global economy (for example, deregulation of capital and credit markets, currency reform and trade-opening) occurred. During this period, approximately since the beginning of the 1990s, geographical agglomeration in the north of Taiwan has intensified and regional inequality seems to have increased (Andersson and Klinthäll 2012). The questions to be addressed are if the distributional effects of agglomeration during this process have been limited or widespread, and what this geographical dimension of inequality implies for the Taiwanese 'growth with equity' pattern.

Through the use of variations of basic Mincer models, nationally representative annual data from household surveys enable us to pursue a detailed analysis of income effects of agglomeration on different educational segments and sectoral employment groups, thus providing micro evidence for macro events. The results confirm that the agglomerating forces have generated an increasing gap between the north and the rest of Taiwan, where more educated household heads have benefitted both compared to their counterparts in the rest of the regions and compared to household heads with lower education within the north. However, the lower educational segments in the north have been able to reap some of the benefits of agglomeration. Taken together, the analysis suggests that although regional divergence gives extra bonus to the highly educated, positive externalities are also 
forwarded to the less educated in the leading region. The implications of the observation that distant (inter-regional) is stronger than proximate (intra-regional) income divergence might be due to geographical proximity matters not only for growth and innovation, but also as a distributive mechanism - but only in a geographically limited space. The conclusion is reached that the mechanisms of 'growth with equity' in Taiwan have altered and become confined to the leading region rather than the country as a whole.

The rest of the paper is organised as follows: section two discusses the different assessments made on how regional inequality has developed over time with a particular focus on the period of increasing globalisation and associated industrial changes over the last decades. A brief and stylised background to Taiwan is also introduced. In section three, the household survey data and choice of methods are presented. Section four analyses the process of regional convergence and divergence in Taiwan from 1976 to 2006 with special attention given to how the geographic agglomeration and process of regional divergence has affected different educational and occupational groups. Section five constitutes the concluding remarks.

\section{Regional divergence, agglomeration and inequality}

One of the main general lessons in the literature on spatial economic dynamics is that regional income disparities tend to follow an inverted U-curve (Williamson 1965; Kuznets 1966; Combes et al. 2011; Kim 1995; Paluzie et al. 2004; Barrios and Strobl 2009). While initial regional divergence in the early part of the process of industrialisation has been explained by industrial geographical agglomeration experiencing positive externalities (for instance, Myrdal 1957; Hirschman 1958), the convergence part of the curve follows the expectations of factor price equalisation (made possible by falling costs of transportation) in 
accordance with neo-classical theory. This latter trend has, over the post-WWII period, been found in empirical studies in many developed countries (see Barro and Sala-i-Martin 1992, 1995; Persson 1997).

Whether or not this pattern will continue in an era of increasing globalisation has been subject for debate over the last decades. That differences in income due to geographical factors should diminish as a consequence of free trade and deregulation (globalisation) is, in certain quarters, a strongly held belief (O’Brien 1992; Ohmae 1995; Cairncross 2001; Friedman 2006). One of the chief reasons why spatial income differences should be evened out both within and between countries is that free trade would increase returns to the abundance of labour underemployed in the developing world. The opening up of a formerly closed economy could also weaken the forward and backward linkages built up during import-substitution and make economic activities more evenly spread out in developing countries (Krugman and Livas 1996).

However, an increasing number of studies are pointing in the opposite direction: spatial income inequality in developed and developing countries alike is rising and it is roughly coincidental with the rise of trade liberalisation and globalization (Zhang and Zhang 2003; Kanbur and Venables 2005; Rodríguez-Pose and Gill 2006; Hanson 2007). One reason for growing regional disparities in developing countries might be that trade liberalisation increases labour's mobility towards industrial agglomeration (Paluzie 2001), specifically in countries that are becoming more engaged in the trading of manufactured goods (Rodríguez-Pose and Gill 2006). Also, in developed economies, it seems as if globalisation fosters local level development (Storper 1995, 1997). Hence, it seems as if evidence is mounting up in favour of the view that globalisation in general, or trade liberalisation in 
particular, tends to increase regional disparity. In terms of long-term regional development, the inverted $U$ curve has taken a new turn.

As far as the impact of ICT on regional development is concerned, some argue that it enables near cost-less transfer of information allowing economic activity to be more outspread and not tied to traditional physical and natural endowments (Quah 2001). Others, however, argue that the shift to a knowledge and ICT oriented economy will strengthen spatial agglomeration (Saxenian 1994; McCann 2008). Even if the causal effects of globalisation and technology shifts are difficult to isolate and are beyond the scope of the present paper, agglomeration is an observable fact of economic development and much is still unknown in terms of its distributional effects on different groups within and outside an agglomerating region. The literature seems to indicate that agglomeration increases growth and efficiency through a variety of channels such as localised spill-overs, clustering of the educated workforce and larger availability of intermediate inputs for enterprises (for instance, Jaffe et al. 1993). The studies made on agglomeration and inequality, based on micro level data, are relatively few and the lack of available household survey data over a sufficiently long period of time makes it hard to find conclusive evidence. This might be due to the fact that the unit of analysis might differ, as might the geographical scales and quality and type of data as well as how data is modelled. A study of regional per capita income inequality based on household data in Western Europe finds that the overwhelming part of overall inequality is intra-regional rather than inter-regional, or between countries (Rodríguez-Pose and Tselios 2008). Another micro data-based study suggests that agglomeration is likely to generate inequality in income distribution between individuals in leading and lagging regions (Duranton and Monastiriotis 2002). In yet another, more theoretical paper, the authors suggest that even if inequality increases, the relatively 
disadvantaged in the lagging regions might still be better off in absolute terms (Fujita and Thisse 2003). What is less investigated is whether inter-regional inequality increases for all major educational and occupational groups and the extent to which less educated groups in the leading region are positively affected by the effect of agglomeration.

The stylised facts of Taiwan relate to many of the theoretical and empirical observations and limitations described above. From the early 1960s, Taiwanese growth was largely based on small-and medium-sized firms geographically distributed in a decentralised pattern (Fei et al. 1979; Ho 1979). Even if the reasons behind the dispersed localisation of rural industries are contested (see Amsden 1991; Greenhalgh 1988; Park and Johnston 1995; Chan et al. 1998), one significant consequence was the cushioning of the income inequality otherwise commonly appearing during the industrialisation process (Fei et al. 1979). Accordingly, Taiwan remained fairly egalitarian as the process of industrialisation did not concentrate income in certain spatial areas or among certain segments of the population (Bourgignon et al. 2001). The rural-urban and the inter-regional income gaps could, therefore, be kept relatively narrow and continue to converge until the early 1990 s.

In common with many industrialising economies during the 1980s, Taiwan entered into what often is labelled 'the third industrial revolution', where new skills and technology gained importance. In Taiwan, production costs had increased abruptly after the appreciation of the New Taiwan Dollar after the Plaza Accord in 1985, and traditional labourintensive industry lost competitiveness. In the late 1980s to early 1990s, most of these firms closed down, moved abroad or restructured (see Feenstra and Hamilton 2006). As a consequence, new and old entrepreneurs entered industrial and service activities that were more intensive in the use of technology and knowledge. 
One indicator of the strong and rapid movement towards the knowledge economy is the substantial decline of the share of blue-collar production workers compared with other occupational categories during the 1990s. The share of production workers can be considered a proxy measure of the strength of the labour intensive industry. Figure 1 shows this significant change and indicates also that the share of production workers started to decrease earlier in the north.

Figure 1 Production workers, share of all occupational categories in Taiwan 1976-2005.

All this resulted in a surge in knowledge intensive industries, located in the north of Taiwan, and a decline in the traditional industries such as textiles and light manufacturing. That the north is the leading region in Taiwan where high-tech manufacturing and service industries are clustered is a well-established observation (Mathews 1997; Saxenian and Hsu 2001; Hu et al. 2005; Lee 2006). What can also be observed is a corresponding rise in the relative importance of the occupational category 'technicians and associate professionals', as the more knowledge intensive industry gained strength during the 1990s (Survey of Family Income and Expenditure in Taiwan). Household survey data shows that the increase in the share of this occupational category compared to other occupations increased more in the north than in the rest of Taiwan. Furthermore, within the manufacturing industry, the long-term decrease in the share of production workers and the increase in the share of technicians imply that technicians and associate professionals outnumbered production workers by the year 2000, and by the end of our investigation period the share of technicians is considerably higher. Typical of Taiwan is the relatively high degree of dynamics on the labour market. In Taiwan, worker mobility is high in an international comparison, and 
inter-regional migration in Taiwan is relatively extensive (Tsou et al. 2001; Chiang 2009). This suggests that regional income inequality is not severely affected by mismatching supply and demand factors on the labour market.

Taking the changes in industrial structure described above as a background, the study now proceeds to examine distributional impacts of the north forging ahead. In order to estimate these effects on educational and occupational categories, modified versions of basic income models are run for each separate year. The coefficients are presented consecutively in figures in order to graphically illustrate the trends. The data and methods are presented below.

\section{Data and methods}

The empirical analysis uses the Survey of Family Income and Expenditure in Taiwan (SFIET), a national survey that was launched for the first time in 1964 , and has been conducted annually since 1976 . The 31 surveys from 1976-2006 cover between 8,933 and 14,974 households per year, adding up to a total sample of 390,802 households and approximately 1.6 million household members. The survey data from 2007 and later do not include information on household location and is, therefore, not used in this study. Each survey provides a cross-section of the Taiwanese economy at the household level, a snapshot for a given year regarding information on household characteristics, incomes and expenditures, housing classification, fixed assets and characteristics of household head and of household members. The analyses of each year's survey data provide annual measures of income disparity across several dimensions (intra- and inter-regionally, by education, occupation, sector of employment, etc.), with the opportunity of taking account of demographic and other characteristics of the household or household head. The time series' presented in the 
analysis section are constructed from coefficients from 651 regression estimations, or 31 estimations per time series, where either household characteristics (figure 2) or characteristics of the household head (figures 3-6) are controlled for. The coefficients are put together chronologically in order to illustrate trends of income disparity over time. Hence, the time series' coefficients are devoid of inflation and are consistently based on nationally and regionally representative data. Thus, annual micro level data is used in order to approach macro level phenomena. Confidence intervals are not plotted due to the use of moving averages, but statistical significance is reported in the text. The coefficients reported in figures 3-6 are boiled-down estimates of income of household heads within and outside the agglomerating north and between occupational and educational categories. In the regression estimations, we take account of socio-economic variables in order to capture the effect of locality on income. In this way, we are able to estimate the distributional consequences of agglomeration. Only the households where the household head is at least 18 years old and not older than 65 years were selected. Households with more than 10 members were excluded. With these limitations, our sample still includes more than 95 per cent of the households in the SFIET 1976-2006.

Up until 2006, the data contains information on the location of the household at the city or county (hsien) level, and follows the standard division of regions in Taiwan - north, central, east and south. These regions have essential characteristics in that the north holds the nation's administrative and political centre of Taipei and is later also the home to much of the semi-conductor industry; the central, where Taichung is the major city and known for much of the labour intensive industry (for example textile and footwear); the south, hosting Kaohsiung as its major city and the home to heavy industry such as petrochemical, steel mill and ship-building (see, for instance, Hsu and Cheng 2002); and the east is a sparsely 
populated peripheral area. The regions in Taiwan are not administrative entities per se, which means that spatial differences are not due primarily to different economic policies of the regions. ${ }^{1}$ Hence, public spending does not correspond to this regional division. In terms of regional population in the mid-2000's, 44 per cent resided in the north, 25 per cent in the central, three per cent in the east and 28 per cent lived in the south (URDS 2006). In the empirical analysis, we divide Taiwan into north and non-north, in which the latter contains all regions outside the north, since the major focus is on the distributional effects of agglomeration; within and outside an agglomerating region.

By comparing income performance over time and across regions and industries, taking account of socio-economic factors at the micro level, patterns of divergence and convergence between leading and lagging regions are identified. The main approach is to construct time series' based on coefficients derived from variations of Mincer-type income equations. Hence, based on calculations of repeated cross-sections, income convergence and divergence over time within and between regions and for different categories of the work force are measured, controlling for skills and experience and demographic characteristics of household heads. Households are classified according to region of location (north or non-north), and the regression models are run for each SFIET cross-section 19762006 in order to obtain annual estimates of a) the effect of the location of the household on income within different categories in the work force, as well as b) effects across categories within the same location.

The SFIET contains ten educational categories, from 'illiterate' to the PhD level, which we grouped into six levels in our analysis. The three lowest educational categories, at the primary level or lower, are grouped together into one ('primary'), and the three highest, at 
college/university, Master's, and PhD levels, are grouped together into one ('college or university').

Regarding occupational categories, the data is more complicated due to reclassification of several occupational categories in the SFIET over time. Certain classifications are, however, stable over time, which means that relative incomes can be analysed for the whole time-period. 'Professional' and 'administrative and executive workers' are two categories that can be followed over the whole time-period, and they include high-income occupations that can be expected to have gained in the process of increased agglomeration. In other cases we have merged occupations into broader categories, such as 'sales and service workers' and 'production workers and machine operators'.

\section{Distributional effects of agglomeration in Taiwan 1976-2006}

Agglomeration in the north and the rise of Hsinchu as the ICT centre of Taiwan can be illustrated by the development of household incomes in the Hsinchu area, compared with household incomes in the rest of Taiwan. For each survey from 1976-2006, we estimate a simple OLS regression model, where we measure the effect of household location on the logarithm of household income, only controlling for household size to illustrate the average household income development of Hsinchu in relation to Taiwan in general:

$$
\ln Y_{\text {household }}=\alpha+\beta_{1} \text { Location }=H \text { sinchu }+\beta_{2} \text { HHsize }+\varepsilon
$$

In figure 2, the $\beta$-coefficients of the location indicator (location=Hsinchu) for each estimation are plotted chronologically. The series of coefficients illustrate the income gap 
between Hsinchu and the rest of Taiwan. Figure 2 shows an initial upwards trend peaking in 1987, reflecting the growth of manufacturing industry in the area. The peak is followed by a temporary backlash until 1993, which illustrates the restructuring effect of the Plaza Accord, when labour intensive manufacturing gave way for more skill-intensive production. After 1993, there is a steep upturn until the year 2000, showing how the ICT-industry takes off and affects incomes in the area positively. Finally, there is a slight downturn, indicating that the ICT-bust of the early 2000s affected household income more negatively in the Hsinchu area than in the rest of Taiwan. Nevertheless, the trend of increasing household income over the period is a clear indication of the relatively higher returns to ICT-activities in the north

Figure 2 Household income gap, Hsinchu vs. rest of Taiwan 1976-2006.

The increasing regional income disparity from the early 1990s onwards thus seems to be explained by a shift towards knowledge intensive production, which has been concentrated in the north, especially, but not exclusively, in Hsinchu. Hence, one would also expect an increasing concentration of highly-skilled workers in the north, and that most of the increased income disparity would be explained by an increasing level of education in the north. Part of the divergence in Taiwan can be attributed to a concentration of skills in the leading region. It is to be expected that wages and income in general are higher in areas specialised in more skill-intensive industries, and the northern region of Taiwan provides an example of this phenomenon from the early 1990s onwards. However, we will show that, taking into account individual skills (proxied by education), per capita incomes are still higher 
in the leading region, which suggests the existence of a locational effect - a geographical agglomeration bonus - adding a premium on top of the skill effect for the population in the most advantageous region.

Next, the study investigates the distributional dimension and asks whether a geographical bonus in the north is primarily enjoyed by the highly educated workers in knowledge-intensive production or whether positive externalities of agglomeration are diffused to the broader segments of the population by investigating relative income trends across educational and occupational categories. We analyse intra-regional as well as interregional income trends. Intra-regional income trends show how relative incomes between educational and occupational categories have changed within the region in the process of industrial transformation. Inter-regional income trends reveal income patterns over time for educational and occupational categories in the north relative to the same categories outside the north; that is, how household heads in these categories have gained in relative terms from working in the leading region.

Looking first at intra-regional income differences between educational categories, the effect of education level on the income of the household head is estimated, controlling for age, sex and civil status, and with separate estimations for households located within and outside north. As mentioned above, the SFIET contains ten educational categories, which we have grouped into six levels. In the regression, education is introduced as six dummy variables, and the regression is estimated for each of the 31 cross sections 1976 to 2006.

$$
\ln Y_{\text {hhead }}=\alpha+\beta_{1} E d u 2+\ldots .+\beta_{5} E d u 6+\beta_{6} \text { Age }+\beta_{7} A g e^{2}+\beta_{8} S e x+\beta_{9} \text { Civstat }+\varepsilon
$$


The coefficients for the education-dummies reflect the income difference for each year from 1976-2006 between each educational category and the reference category (primary), and in figures $3 a$ and $3 b$, they are plotted in time-series diagrams.

Figure 3a shows that there is a clear trend of increasing returns to education within the north. The two highest educational levels show trends of increasing income relative to the reference category: primary education or less. Within the north, the upwards trend becomes steeper from 1990 for all educational levels above junior high school. Figure 3b shows that the trends are weaker in the regions outside the north, except a long-term trend of increasing relative incomes for those with a college or university education. The differences between all educational categories, except between 'senior high' and 'vocational', are statistically significant at the five per cent level throughout the whole period after 1978, within as well as outside the north. The results indicate that technological change in the north is more skill-biased compared to technological change in the rest of Taiwan.

Figure 3a Relative income by education 1976-2006 within northern Taiwan.

Reference category $=$ Primary education and lower .

Figure 3b Relative income by education in Taiwan outside the northern region 1976-2006. Reference category = Primary education and lower.

According to the estimates reported in figures $3 a$ and $3 b$, the highest educational category has gained the most in relative terms, both within and outside the north. The patterns of increased income disparity across educational categories are similar within and 
outside the north. Higher returns to education both within and outside the north do not, in itself, suggest a particular effect of agglomeration. But the pattern is more accentuated in the north, suggesting that returns to education have increased more in the north, particularly from around 1990.

In order to analyse inter-regional income disparity across educational categories, separate regressions were estimated for each educational category, including an indicator for whether or not the household was located in the north.

$\ln Y\left(\text { Education }_{i}\right)_{\text {hhead }}=\alpha+\beta_{1}$ Location $=$ North $+\beta_{2}$ Age $+\beta_{3}$ Age $e^{2}+\beta_{4}$ Sex $+\beta_{5}$ Civstat $+\varepsilon$

Figure 4a Inter-regional income disparity in Taiwan from 1976-2006 across lower educational categories. North vs. non-north, five-year moving averages. Reference $=$ Nonnorth.

Figure 4b Inter-regional income disparity in Taiwan from 1976-2006 across higher educational categories. North vs. non-north, five-year moving averages. Reference $=$ Nonnorth.

Five-year centred moving averages of the coefficients for location (north) are plotted separately for each educational category in figures $4 a$ and $4 b$. Note that figures $4 a$ and $4 \mathrm{~b}$ show the relative income advantage in the north compared to the non-north, the reference category is the corresponding educational category outside the north. No regional consumer price index was available to control for possible regional deviations in terms of evolution of 
prices. Even if housing prices seem to be higher in the north, it seems more reasonable to see this as an effect of agglomeration rather than its cause (Hsueh et al. 2002). Figures 4a and $4 \mathrm{~b}$ show that increasing agglomeration bonus in the north is a general phenomenon and not just confined to high-skilled labour. What is noteworthy is that the inter-regional income gap is larger within the lower education shown in figure 4a, than within the higher education shown in $4 \mathrm{~b}$. At the beginning of the period, those with primary education in the north had about 33 per cent higher incomes than those with primary education in the rest of Taiwan. The income advantage decreased to about 18 per cent for those with primary education in the middle of the period, before increasing again to about 25 per cent at the end of the period. For those with a college or university education, the income advantage was about 18 per cent in the north at the beginning of the period, decreasing to a statistically insignificant level between 1988 and 1990, before increasing again to 17 per cent at the end of the period. Apparently, the increasing regional income disparity in the second part of the period includes all educational categories, not only the higher educations. In relative terms, the regional income gap was actually larger within lower educations. In terms of income of the household heads, it seems that the less educated were better off in the north compared to the rest of Taiwan.

However, the trend of increasing inter-regional income disparity starting in the late 1980s is more pronounced and begins earlier within the higher education categories. The turning points for the lower educations in figure 4a are between 1991 and 1994 and the increase is between five and seven percentage points, whereas the turning points for the higher educations in figure 4b are between 1988 and 1991 and the increase is between 10 and 13 percentage points. Hence, the inter-regional pattern of income convergence followed by divergence is pronounced for all educational categories, suggesting that the increasing 
agglomerating bonus in the north seems to be more immediate and somewhat stronger for the highly educated.

Analysing intra-regional income differences according to occupation, a similar model as above is used; the estimations include control variables for age, sex and civil status of the household head and dummy variables for occupational category (model 1). Separate estimations (model 2) adding controls for education are also included to detect whether the relationship between occupation (tasks) and education (skills) changes over time (cf. Acemoglu and Autor 2011). The estimations are made separately for north and non-north regions, using the 31 surveys for 1976-2006. The five-year moving averages of the coefficients for occupational category are plotted in figures $5 \mathrm{a}$ and $5 \mathrm{~b}$.

Model 1:

$$
\ln Y\left(\text { Occupation }_{i}\right)_{\text {hhead }}=\alpha+\beta_{1} \text { Age }+\beta_{2} \text { Age } e^{2}+\beta_{3} \text { Sex }+\beta_{4} \text { Civstat }+\varepsilon
$$

Model 2:

$$
\ln Y\left(\text { Occupation }_{i}\right)_{\text {hhead }}=\alpha+\beta_{1} \text { Age }+\beta_{2} \text { Age } e^{2}+\beta_{3} \text { Sex }+\beta_{4} \text { Civstat }+\beta_{5} E d u 2+\ldots+\beta_{9} E d u 6+\varepsilon
$$

Figure 5a Intra-regional relative income by occupational category 1976-2006 in northern Taiwan. Reference category = All other occupations.

Figure 5b Intra-regional relative income by occupational category 1976-2006 outside northern Taiwan. Reference category = All other occupations.

Figures $5 \mathrm{a}$ and $5 \mathrm{~b}$ show the income development for high-end occupations and do not provide a direct comparison between the north and the other regions. The figures signal, 
however, that the higher incomes in the north are not explained by disproportional increase of income for high-end occupation compared to the same categories in the rest of Taiwan. Figure $5 \mathrm{a}$ shows the income patterns within the northern region. Relative incomes have increased for high-end occupations: 'administrative and executive workers' display the highest relative incomes over time, between eight and 24 percentage points higher than 'professionals' and between 50 and 69 per cent higher than the reference; all other occupations. All differences are statistically significant on the five per cent level throughout the period. There is a clear trend of increasing incomes from around 1990 for high-end occupations indicated by both 'administrative and executive workers' and 'professionals' relative to other occupations in the north. The tendency of increased income dispersion between high and low income occupations is in line with the tendencies regarding higher and lower educations. Taking account of education, model 2 (dotted lines) shows that education explains a significant part of the level difference for high-end occupations. Regarding administrative and executive workers, the shape of the time series' are basically unchanged over time. Regarding professionals, there is a clear pattern of increasing returns to education from the early 1990s, indicated by the divergence of the series derived from models 1 and 2 . Figure $5 \mathrm{~b}$ shows a somewhat different picture regarding the patterns of relative incomes in the regions outside the north. There is a similar upward trend for 'professionals', whereas there is a slightly negative trend for 'administrative and executive workers', although, from a high level. There is a clear trend break for 'professionals' around 1990, and the intra-regional differences between the two occupational categories in model 1 are statistically insignificant outside the north after that year. Model 2 reveals that education is an important factor for the rising incomes for professionals after 1990. 
Income was more compressed across occupations in the north during the early period and has become more divergent after 1990, implying an increasing premium for high-end occupations. But, compared to the rest of Taiwan, the income gap between high-end occupations and all other occupations is not significantly wider in the north, i.e., other occupations seem to have gained from agglomeration in the north. Controlling for education lowers the income gap vis-à-vis the reference category (all other occupations) since occupation is typically reflected in level of education. What is noteworthy is that 'professionals' is a more heterogeneous category in terms of educational level and that there seems to be a clear change after 1990 when 'professionals' in both the north and the rest of the regions contains an increasingly large share of highly educated individuals. For this category, it seems to be education rather than occupation that pays off after 1990, whereas the relationship between occupation and education for 'administrative and executive workers' is more constant over time and the income premium is, to a larger extent, explained by specific tasks rather than skills. Figures $6 a$ and $6 \mathrm{~b}$ show inter-regional income differences across occupational categories. Again, there are clear trends of income convergence for all occupational categories in the first half of the time period, until the early 1990s. The inter-regional difference is statistically insignificant in the years around 1990 for the high-end occupations displayed in figure 6a. The second part shows a very steep trend of increased divergence for 'administrative and executive workers', a pronounced divergence for 'professionals' and for 'production workers and machine operators', and a small tendency towards increased inter-regional income divergence for 'sales and service workers'.

Model 1:

$\ln Y\left(\text { Occupation }_{i}\right)_{\text {hhead }}=\alpha+\beta_{1}$ Location $=$ North $+\beta_{2}$ Age $+\beta_{3}$ Age $e^{2}+\beta_{4}$ Sex $+\beta_{5}$ Civstat $+\varepsilon$ 
Model 2:

$\ln Y\left(\text { Occupation }_{i}\right)_{\text {hhead }}=\alpha+\beta_{1}$ Location $=$ North $+\beta_{2}$ Age $+\beta_{3}$ Age $e^{2}+\beta_{4}$ Sex $+\beta_{5}$ Civstat $+\beta 6 E d u 2+\ldots+\beta_{10} E d u 6+\varepsilon$

Figure 6a Inter-regional income disparity in Taiwan 1976-2006 across higher-end occupational categories. North vs. non-north, five-year moving averages.

Reference $=$ Non-north .

Figure 6b Inter-regional income disparity in Taiwan 1976-2006 across lower-end occupational categories. North vs. non-north, five-year moving averages. Reference $=$ Nonnorth.

Thus, increasing interregional income divergence is not only confined to the highincome occupations displayed in figure 6a, but also to the more ordinary occupations shown in figure $6 \mathrm{~b}$. When controlling for education, the regional income effect is relatively stronger for the lower end occupations, partly because the variance in education is lower among lower end occupations. Over time, education has a larger effect on income after 1990 for the higher-end occupations, but the U-shaped pattern of inter-regional income development remains for all categories. The occupations within the category 'production workers and machine operators' display steeper inter-regional income divergence compared to 'sales and service workers'. Hence, occupations in the north directly affected by the industrial transformation have gained more in relative terms, but there seems to be spill-over effects on other occupations, for example, within the category 'sales and service workers'. The steep trend regarding 'administrative and executive workers' after 1990 may be an 
indication of central administrative and executive functions being increasingly concentrated to the north in the course of the structural transformation. The geographically decentralised labour intensive industrial pattern, one of the central features of Taiwan's 'growth with equity' model, seems to have been fundamentally altered and replaced by other, weaker, distributive mechanisms between regions. Within the north, however, geographical agglomeration seems to generate its own distributional mechanism through proximity effects.

\section{Conclusions}

Taiwan represents a case that from the 1970s onwards has experienced strong structural changes of the economy, most notably in the direction towards a more skill-and knowledge intensive industry and industrial agglomeration in the north. One of the consequences of these changes is a marked increase in regional income disparity beginning around 1990, after which the northern region had forged ahead. The fundamental question addressed in the paper is whether this spatial inequality is confined to limited segments of the Taiwanese educational and occupational hierarchy, or to people at large in the northern region. The choice of methods, constructing a longitudinal perspective on 31 consecutive household surveys using multiple cross-sectional regression estimations, allows assessments of the extent and distribution of Marshallian proximity effects of agglomeration in the leading region. The U-shaped inter-regional income pattern in Taiwan 1976-2006 seems to be driven by structural change with its core in the manufacturing sector. Increasing interregional income divergence in the second part of the period, from the early 1990s onward is found for all educational categories, showing that the positive income effect of agglomeration in the north is a relatively general phenomenon. 
The results suggest that highly educated and some high end occupations have been particularly successful in reaping the benefits of agglomeration. At the same time, the fruits of agglomeration in the north have also spilled over to lower-educated segments of society within that region. According to the analysis of the data in this study, also, the less educated enjoy positive externalities of agglomeration in the leading region, implying that geographical agglomeration has the potential of lifting all boats in the agglomerating region. By implication, however, 'growth with equity' has become a regional rather than national characteristic of Taiwan and, as such, the interplay between the industrialisation process and inequality has increasingly become dependent upon regional growth dynamics. Comparative analysis would reveal whether other East Asian countries follow the Taiwanese pattern and the extent to which the second-tier Asian countries would be wise to pay closer attention to regional growth dynamics in their quest for equitable growth.

\section{Acknowledgements}

The authors are grateful for the comments received from two anonymous referees of this Journal. Support from the Swedish Research Council is also gratefully acknowledged.

\section{Notes}

1. The administrative units of Taiwan are the central municipalities (Taipei and Kaohsiung), five large provincial cities and 16 prefectures including an intermediate size prefectural city, towns and rural districts.

\section{Notes on contributors}


Martin Andersson is an Associate Professor in Economic History at Lund University, Sweden. His research interests include agricultural development and the relation between economic growth and distribution in the developing world. He has published journal articles and books on economic development and structural change in East Asia, Sub-Saharan Africa and Latin America.

Martin Klinthäll is an Associate Professor in Economic History at Linköping University, Sweden. His research interests involve economic demography and labor market dynamics in Sweden and East Asia. He has published a wide range of journal articles on migration, labor market integration and structural change.

\section{References}

Acemoglu, D. and Autor, D. 2011. "Skills, tasks and technologies: Implications for employment and earnings." Handbook of Labor Economics 4b: 1043-1171.

Amsden, A. 1991. "Big business and urban congestion in Taiwan: The origins of small enterprise and regionally decentralized industry (respectively)." World Development vol. 19: 1121-35.

Andersson, M. and Klinthäll, M. 2012. "The opening of the north-south divide: cumulative causation, household income disparity and the regional bonus in Taiwan 1976-2005." Structural Change and Economic Dynamics 23: 170-79.

Ascani, A., Crescenzi, R. and lammarino, S. 2012. "Regional economic development: A review." SEARCH WP 1/03.

Barrios, S. and Strobl, E. 2009. "The dynamics of regional inequalities." Regional Science and Urban Economics 39: 575-91. 
Barro, R. J.and Sala-i-Martin, X. 1992. "Convergence." Journal of Political Economy 100 (2): 223-51.

Barro, R. J. and Sala-i-Martin, X. 1995. Economic Growth. New York: McGraw-Hill.

Bourgignon, F., Fournier, M. and Gurgand, M. 2001. "Fast development with a stable income distribution: Taiwan, 1979-94." Review of Income and Wealth 47 (2): 139-63.

Cairncross, F. 2001. The Death of Distance - How the Communications Revolution Is Changing Our Lives. USA: Harvard Business School Press.

Chan, S., Clark, C. and Lam, D. 1998. Beyond the Developmental State - East Asia's Political Economies Reconsidered. Great Britain: Macmillan.

Chiang, S-H. 2009. "The effects of regional diversity on national unemployment through inter-regional migration: new evidence from Taiwan." Applied Economics 41: 2505-11.

Combes, P-P., Lafourcade, M., Thisse, J-F. and Toutain, J-C. 2011. "The rise and fall of spatial inequalities in France: A long-run perspective." Explorations in Economic History 48: 243-71.

Dupont, V. 2007. “Do geographical agglomeration, growth and equity conflict?" Papers in Regional Science 86 (2): 193-213.

Duranton, G. and Monastiriotis, V. 2002. « Mind the gaps: The evolution of regional earnings inequalities in the U.K., 1982-1997." Journal of Regional Science 42 (2): 219-56.

Fagerberg, J. and Verspagen, B. 1996. "Heading for divergence? Regional growth in Europe reconsidered." Journal of Common Market Studies 34: 431-48.

Feenstra, R.C. and Hamilton, G.G. 2006. Emergent Economies, Divergent Paths - Economic Organization and International Trade in South Korea and Taiwan. New York: Cambridge University Press. 
Fei, J., Ranis, G. and Kuo, S.W.Y. 1979. Growth with Equity: The Taiwan Case. Washington DC: Oxford University Press.

Feng, W. 2011. “The end of 'Growth with equity'? Economic growth and income inequality in East Asia." Asia Pacific Issues. Analysis from the East-West Centre, No. 101 (July).

Friedman, J. 2005. The World is Flat: A Brief History of the Twenty-First Century. New York: Farrar, Straus, and Giroux.

Fujita, M. and Thisse, J-F. 2003. "Does geographical agglomeration foster economic growth? And who gains and loses from it?" The Japanese Economic Review 54 (2): 121-45.

Glaeser, E.L., Kallal, H.D., Scheinkman, J.A. and Shleifer, A. 1992. "Growth in cities." Journal of Political Economy, 100 (6): 1126-52.

Goldin, C. and Katz, L. 2008. The Race between Education and Technology. Cambridge: Harvard University Press.

Greenhalgh, S. 1988. "Families and networks in Taiwan's economic development." In Contending Approaches to the Political Economy of Taiwan edited by Winckler, E. and Greenhalgh, S. Armonk: ME Sharpe.

Hamaguchi, N. 2009. "Regional integration, agglomeration, and income distribution in East Asia." In Reshaping Economic Geography in East Asia edited by Huang, Y. and Bocchi, A.M. The World Bank.

Hanson, G.H. 2007. "Globalization, labor income and poverty in Mexico." In Globalization and Poverty edited by Harrison, A. Chicago: University of Chicago Press.

Hirschman, A.O. 1958. The Strategy of Economic Development. New Haven: Yale University Press.

Ho, S.P.S. 1979. "Decentralized industrialization and rural development: Evidence from Taiwan." Economic Development and Cultural Change 28 (1): 77-96. 
Hsu, J-Y. and Cheng, L-L. 2002. "Revisiting economic development in post-war Taiwan: The dynamic process of geographical industrialization." Regional Studies 36 (8): 897-908.

Hsueh, L-M., Li, C-W. and Tseng, H-P. 2002. "The population migration in Taiwan, and its causal relationship with labor market and housing market." International Real Estate Review 5 (1): 61-90.

Hu, T-S., Lin, C-Y. and Chang, S-L. 2005. "Role of interaction between technological communities and industrial clustering in innovative activity: The case of Hsinshu district, Taiwan." Urban Studies 42 (7): 1139-60.

Jaffe, A., Trajtenberg, M. and Henderson, R. 1993. "Geographical localization of knowledge spillovers as evidenced by patent citations." Quarterly Journal of Economics 108: 57798.

Kanbur, R. and Venables, A.J., eds. 2005. Spatial Inequality and Development, WIDER studies in Development Economics. USA: Oxford University Press.

Kim, S. 1995. "Expansion of markets and the geographic distribution of economic activities: The trends in U.S. regional manufacturing structure, 1860-1987." Quarterly Journal of Economics 110 (4): 881-908.

Kim, S. 2008. "Spatial inequality and economic development: Theories, facts, and policies." Commission on Growth and Development, WP 16.

Krugman, P. and Livas, R.E. 1996. "Trade policy and the Third World metropolis." Journal of Development Economics 49: 137-50.

Kuznets, S. 1966. Modern Economic Growth - Rate, Structure and Spread. Clinton Mass. USA: Yale University Press.

Lee, T.L. 2006. "Action strategies for strengthening industrial clusters in southern Taiwan." Technology in Society 28: 533-52. 
Marshall, A. 1890. Principles of Economics. London: Macmillan.

Mathews, J.A. 1997. "A Silicon Valley of the East: Creating Taiwan's semiconductor industry." California Management Review, 39 (4): 26-54.

McCann, P. 2008. "Globalization and economic geography: the world is curved, not flat." Cambridge Journal of Regions, Economy and Society 1: 351-370.

Myrdal, G. 1957. Economic Theory and Underdeveloped Regions. London: Duckworth

O'Brien, R. 1992. Global Financial Integration: The End of Geography. London: Royal Institute of International Affairs.

OECD 2011. Divided We Stand: Why Inequality Keeps Rising. OECD.

Ohmae, K. 1995. The Borderless World: Power and Strategy in an Interdependent Economy. New York: Harper Business.

Paluzie, E. 2001. "Trade policy and regional inequalities." Papers in Regional Science 80 (1): $67-86$.

Paluzie, E., Pons, J. and Tirado, D.A. 2004. "The geographical concentration of industry across Spanish regions, 1856-1995." Review of Regional Research 24 (2): 143-60.

Park, A. and Johnston, B. 1995. "Rural development and dynamic externalities in Taiwan's structural transformation." Economic Development and Cultural Change 44 (1): 181208.

Persson, J. 1997. "Convergence across the Swedish counties, 1911- 1993." European Economic Review 41 (9): 1835-52.

Petrakos, G. 2001. "Patterns of regional inequality in transition economies." European Planning Studies 9: 359-83.

Puga, D. 2002. "European Regional Policies in Light of Recent Location Theories." Journal of Economic Geography 2 (4): 372-406. 
Quah, D. 2001. "ICT clusters in development: Theory and evidence." Mimeo, LSE Economics Department.

Rey, S.J. and Janikas, M.V. 2005. "Regional convergence, inequality, and space." Journal of Economic Geography 5: 155-76.

Rodríguez-Pose, A. and Gill, N. 2006. "How does trade affect regional disparities?" World Development 34 (7): 1201-22.

Rodríguez-Pose, A. and Tselios, V. 2008. “Mapping regional personal income distribution in Western Europe: Income per capita and inequality." Dynamic Regions in a KnowledgeDriven Global Economy: Lessons and Policy Implications for the EU, WP 33.

Sanchez-Reaza J. and Rodríguez-Pose A. 2002. "The impact of trade liberalization on regional disparities in Mexico." Growth and Change 33 (1): 72- 90.

Saxenian, A-L. and Hsu, J-Y. 2001. "The Silicon valley-Hsinchu connection: Technical communities and industrial upgrading." Industrial and Corporate Change 10 (4):893920.

Saxenian, A-L. 1994. Regional Advantage: Culture and Competition in Silicon Valley and Route 128. Cambridge: Harvard University Press.

SFIET. The Survey of Family Income and Expenditure in Taiwan 1976-2006 (annually), Directorate-General of Budget, Accounting and Statistics, Executive Yuan, Republic of China.

Storper, M. 1995. "The resurgence of regional economies, ten years later: The region as a nexus of untraded interdependencies." European Urban and Regional Studies 2: 191221.

Storper, M. 1997. The Regional World: Territorial Development in a Global Economy. New York: The Guilford Press. 
Tsou, M-W., Liu, J-T. and Hammitt, J.K. 2001. "Worker flows and job flows in Taiwan." Economics Letters 73: 89-96.

URDS. 2006. Urban and Regional Development Statistics 2006, Republic of China.

WDR 2009. World Development Report 2009: Reshaping Economic Geography. USA: The World Bank.

Williamson, J.G. 1965. "Regional inequality and the process of national development: A description of the patterns." Economic Development and Cultural Change 13 (4): 3-45.

Zhang, X. and Zhang, K. 2003. "How does globalization affect regional inequality within a developing country? Evidence from China." Journal of Development Studies 39 (4): 4767. 
Figure 1. Production workers, share of all occupational categories in Taiwan 1976-2005.

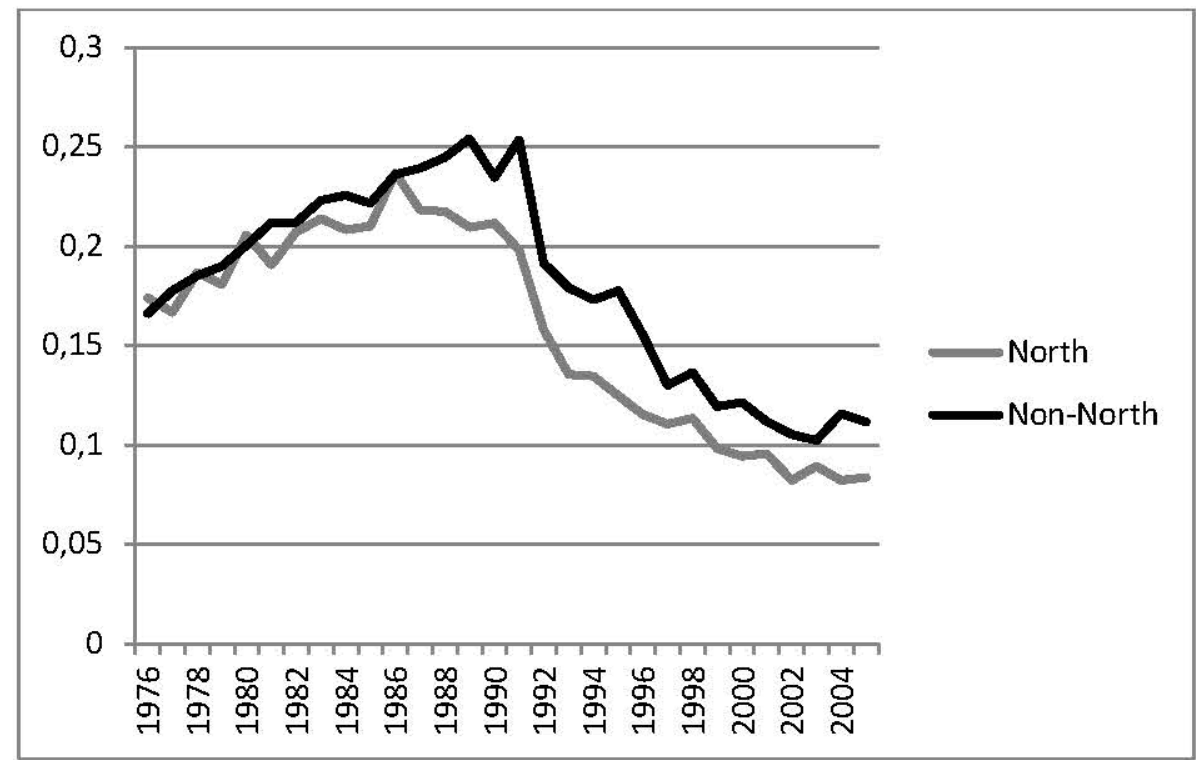

Source: SFIET 
Figure 2. Household income gap, Hsinchu vs. rest of Taiwan 1976-2006.

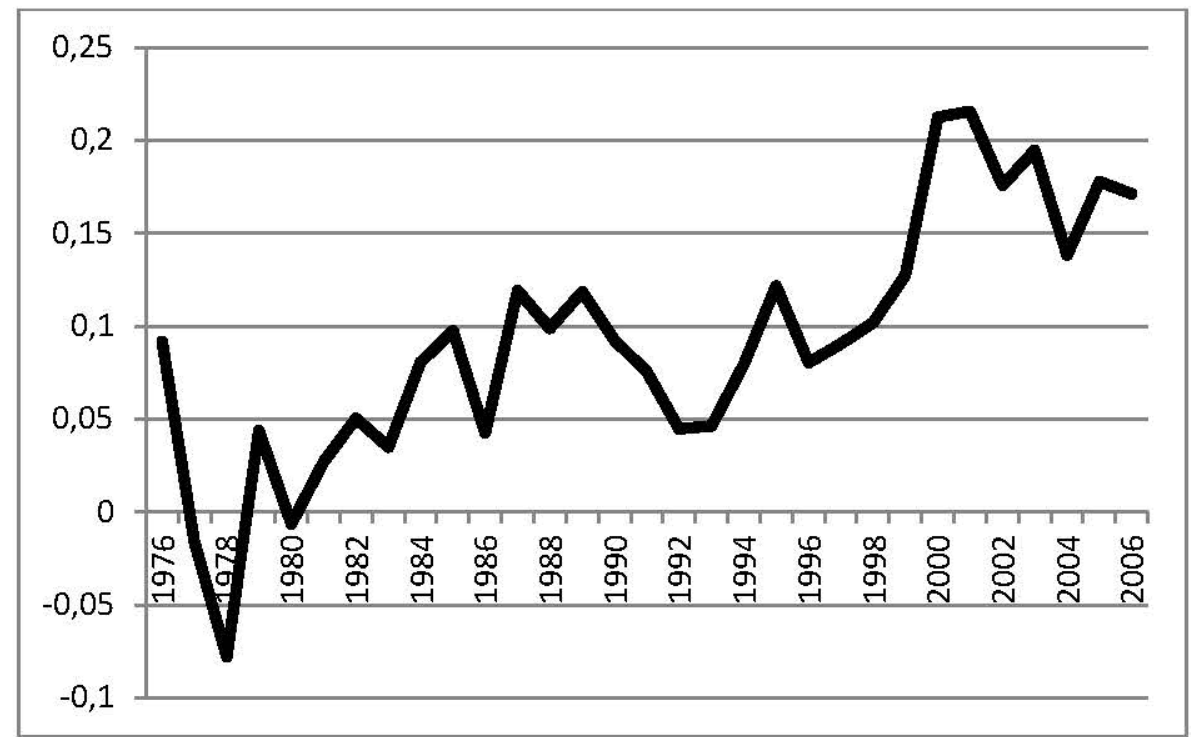

Source: SFIET 
Figure 3a: Relative income by education 1976-2006 within northern Taiwan.

Reference category = Primary education and lower.

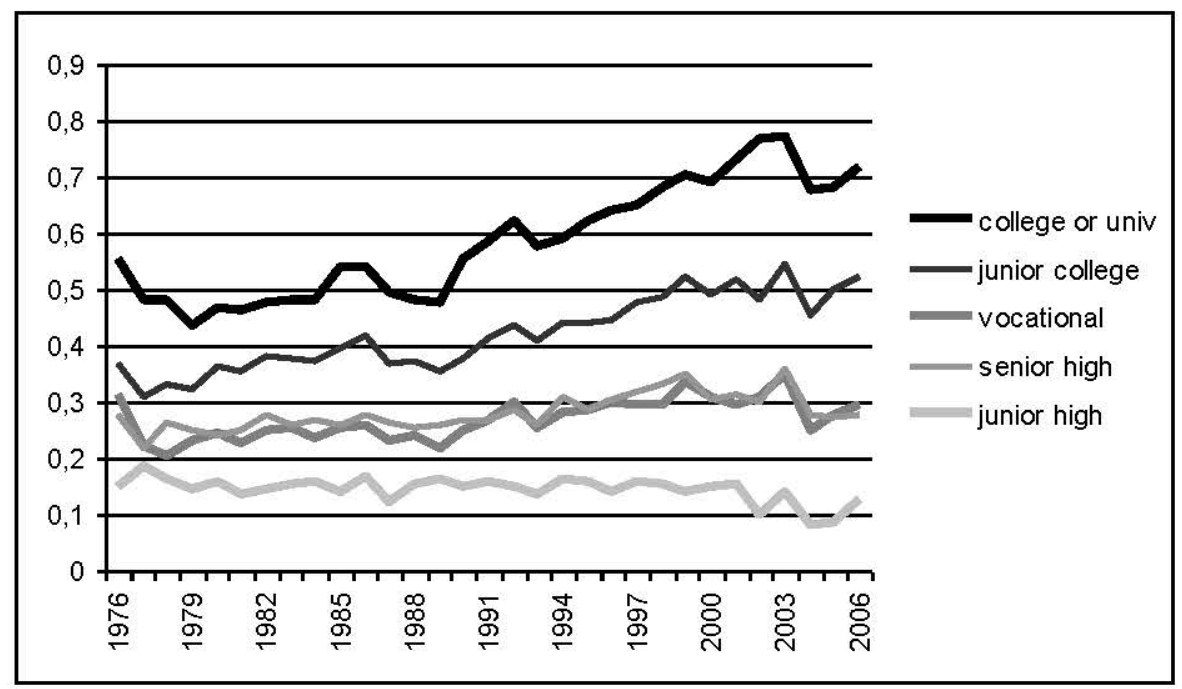

Source: SFIET 
Figure 3b: Relative income by education in Taiwan outside the northern region 1976-2006.

Reference category = Primary education and lower.

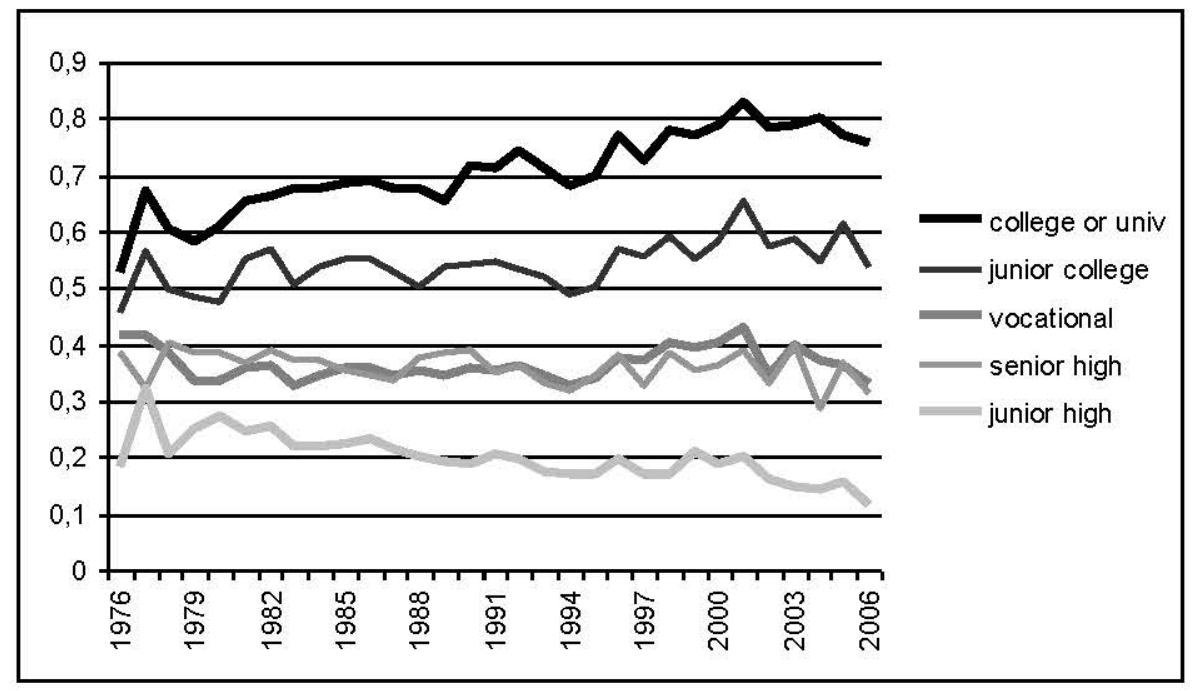

Source: SFIET 
Figure 4a: Inter-regional income disparity in Taiwan 1976-2006 across lower educational categories. North vs. non-north, 5-year moving averages. Reference $=$ Non-north

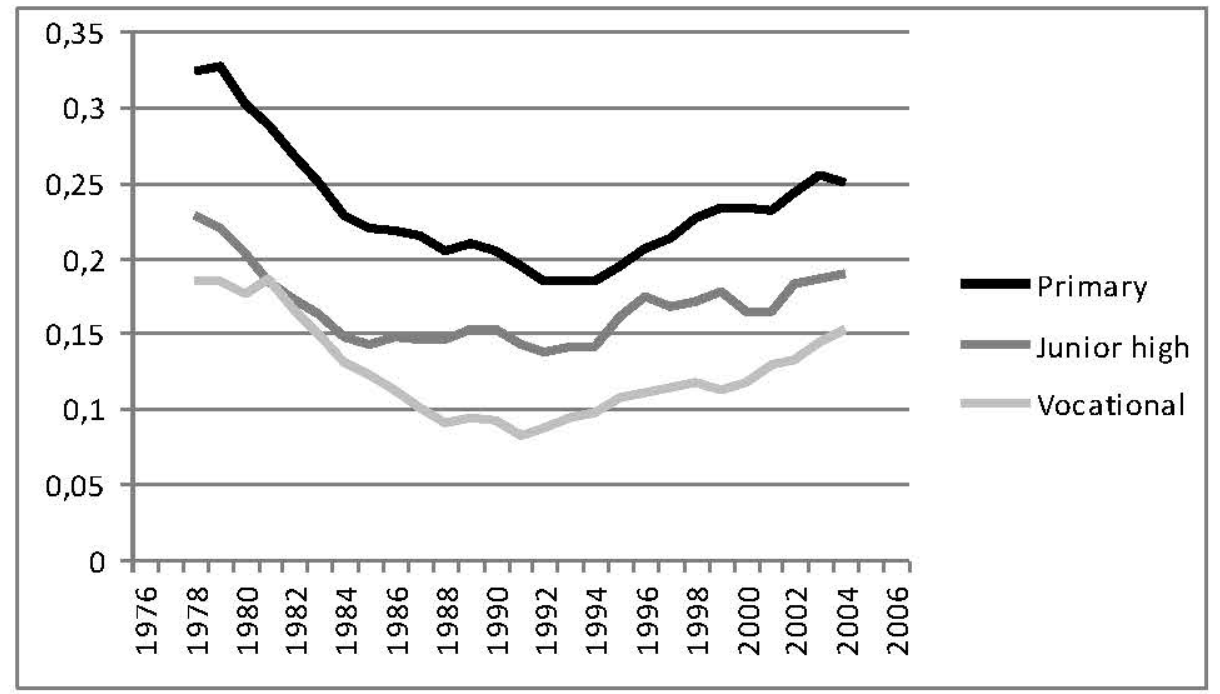

Source: SFIET 
Figure 4b: Inter-regional income disparity in Taiwan 1976-2006 across higher educational categories. North vs. non-north, 5-year moving averages. Reference = Non-north.

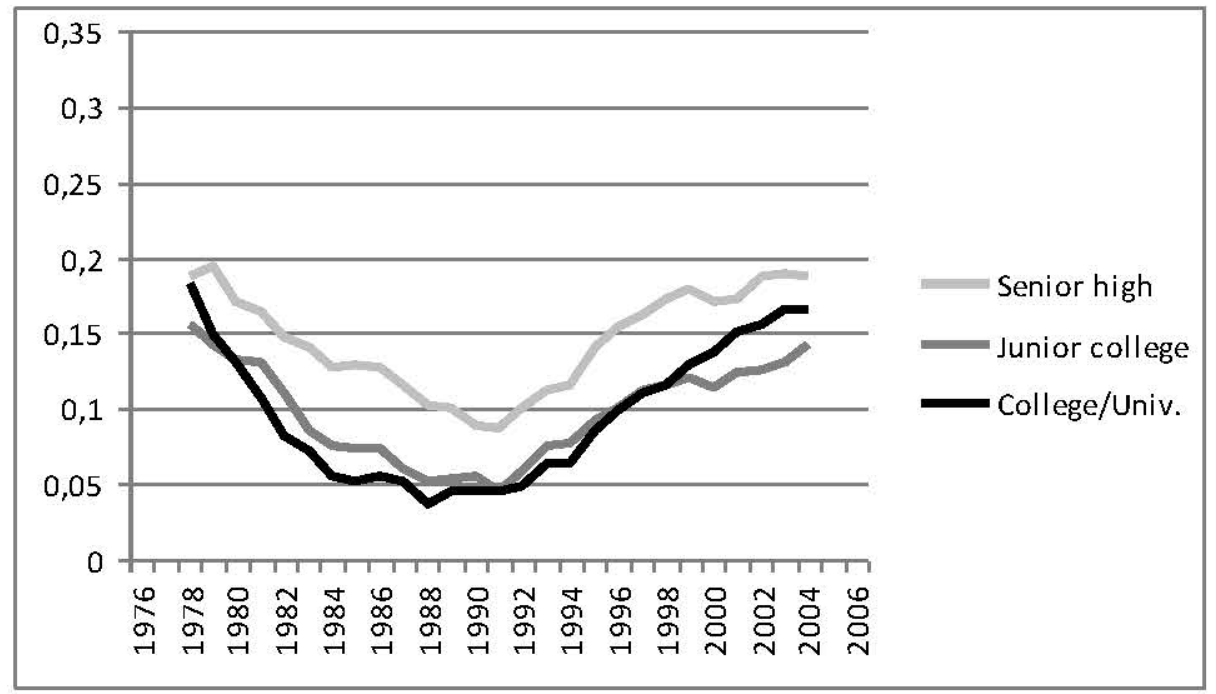

Source: SFIET 
Figure 5a: Intra-regional relative income by occupational category 1976-2006 in northern Taiwan. Reference category = All other occupations.

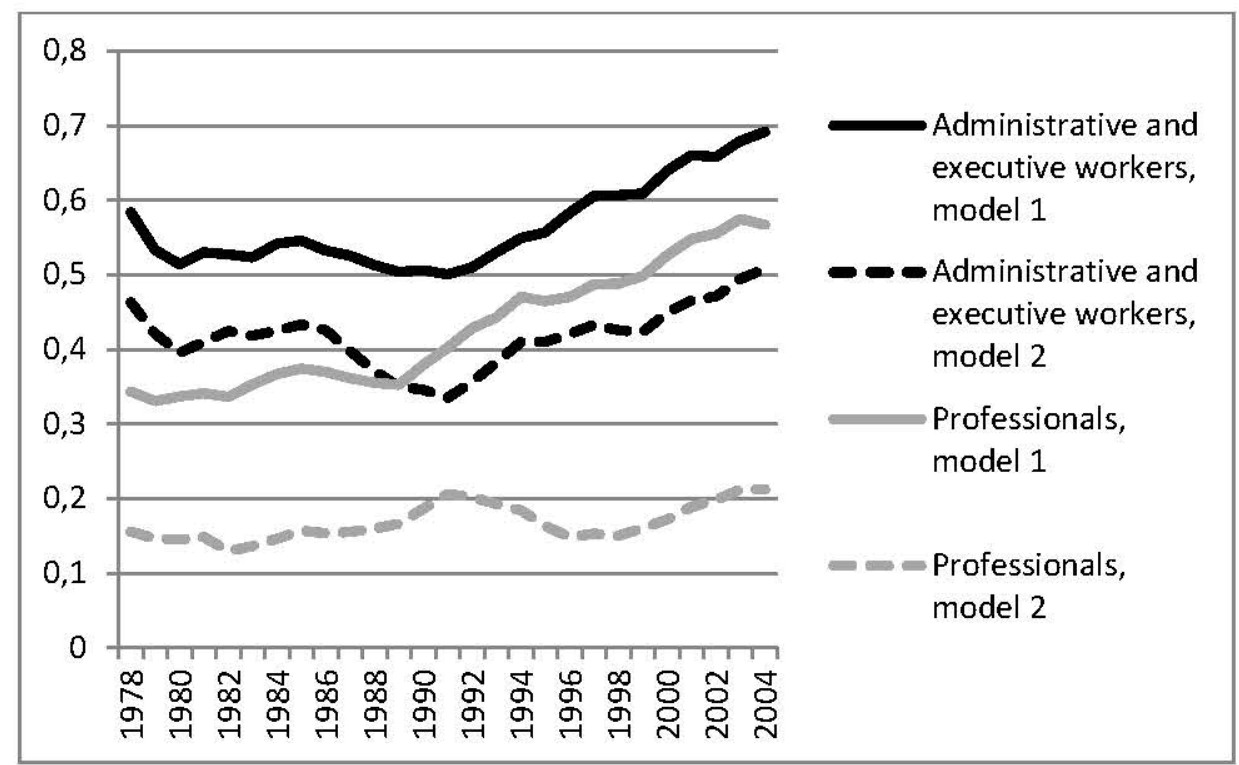

Source: SFIET 
Figure 5b: Intra-regional relative income by occupational category 1976-2006 outside northern Taiwan.

Reference category $=$ All other occupations.

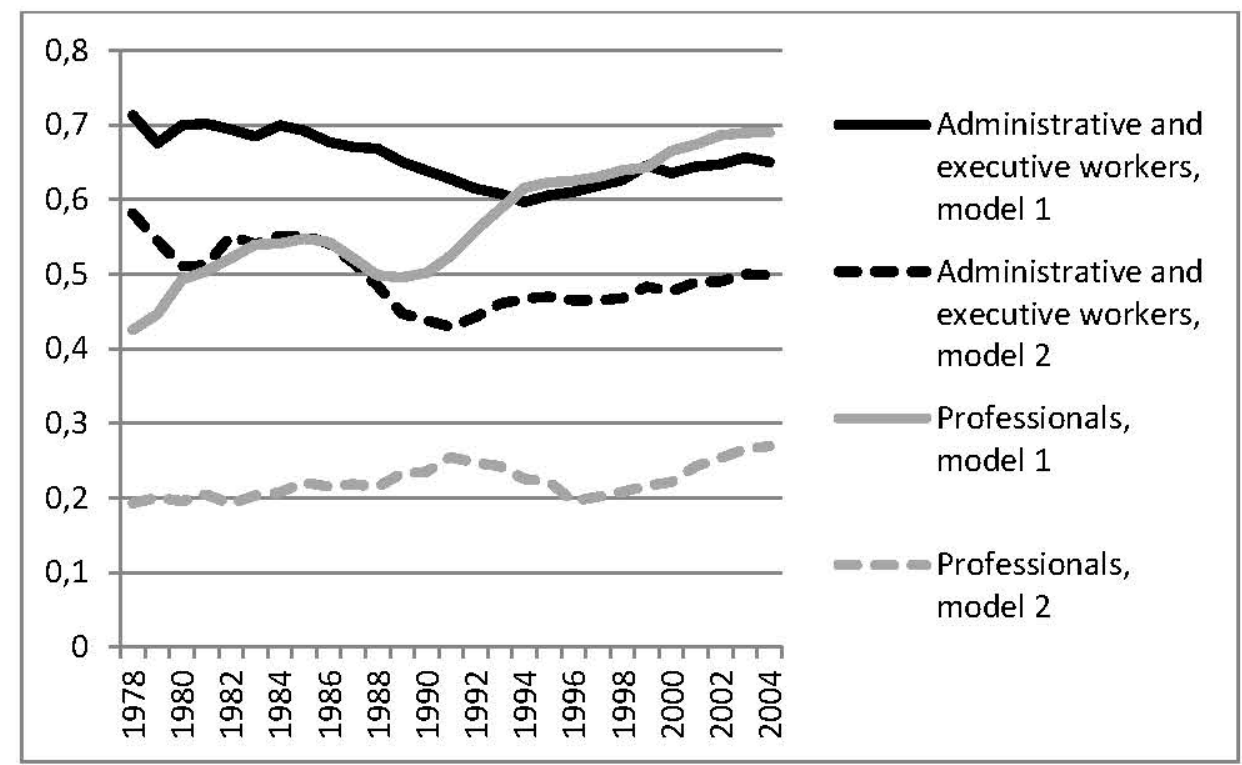

Source: SFIET 
Figure 6a: Inter-regional income disparity in Taiwan 1976-2006 across higher-end occupational categories. North vs. non-north, 5-year moving averages.

Reference $=$ Non-north .

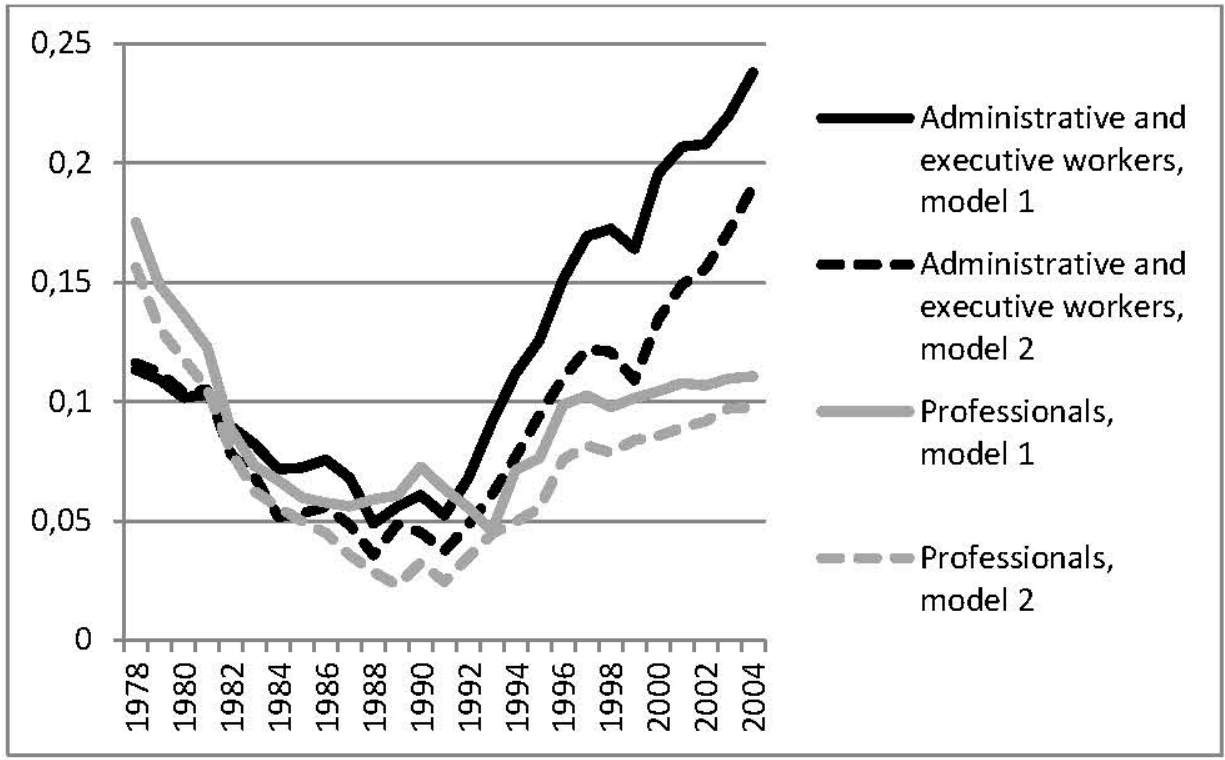

Source: SFIET 
Figure 6b: Inter-regional income disparity in Taiwan 1976-2006 across lower-end occupational categories. North vs. non-north, 5-year moving averages.

Reference $=$ Non-north .

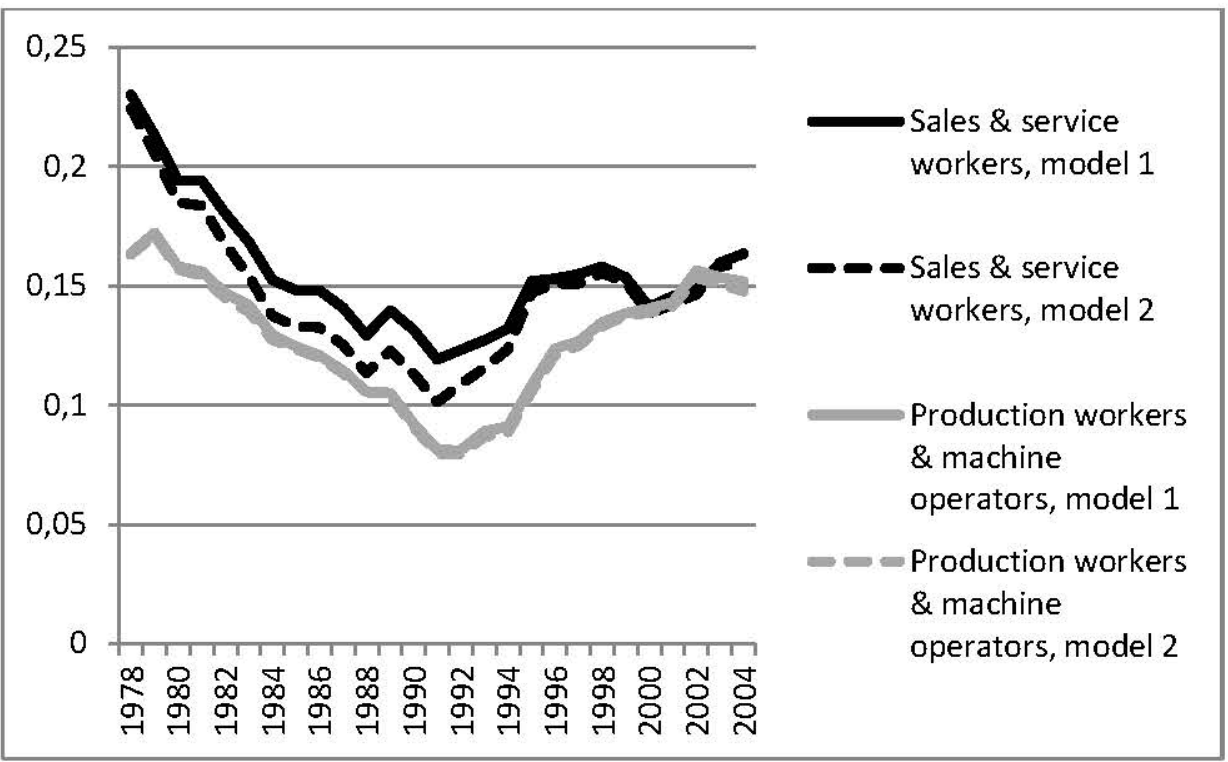

Source: SFIET 